\title{
The realities of change in higher education
}

Lynne Hunt, Adrian Bromage and Bland Tomkinson (Eds), 2006

Abingdon, Routledge

$£ 24.99$ (pbk), 191 pp.

ISBN 0-4I53-8580-6.

There must be one of those irregular verbs which conjugates along the lines of: 'I make careful judgements; you are risk-averse; s/he misses obvious opportunities'. That is to say, the degree to which you support any given organizational change depends to a large extent on how you stand in relation to it. If you are an organizational insider, the likely impact of the change on you will colour your view of its desirability. Even if you make an effort to look beyond a personal cost/benefit analysis and try to assess the proposed change in terms of the organization's goals, your views on the desirability of these goalsor perhaps their meaning - and the best way of achieving them, may not be those of your colleagues. If you are an outsider, perhaps trying to research change, it is next-to-impossible to come to a view that does not merely restate the views of the most plausible insiders to whom you have spoken. Reports of organizational change, then, must be understood as being provisional, subjective and multilayered: as a postmodernist might put it, there can be no grand narrative that explains any particular organizational change.

This conceptual difficulty is a largely neglected problem in the study of the management of change (incidentally, why does the management of stasis always seem to get overlooked?), and this book is no exception. The book's case studies, drawn mainly from American, Australian and UK universities, generally begin with the proposition (implied rather than argued) that the change in question is desirable, the purpose of the study being to show how it was implemented, normally with minimal difficulty; or to discover why, inexplicably almost, the change did not roll smoothly forwards. Thus, Charles Engel and Bland Tomkinson seek to understand 'the structural factors that can inhibit the change process' (p. 156): in this case, the proposed change, of which they were apparently important initiators, was to reorder the curriculum of the post-2004-merger University of Manchester, in the UK, in order 'to embed an interdisciplinary approach to societal responsibilities' ( $p$. 157) across the entire University. The authors describe this proposal, without apparent irony, as the 'Ultimate Challenge' (their capitals).

The failure of the University to rise to this challenge-or Challenge-is analysed in terms of individuals' attachments to the status quo and the undermining of power bases, and of tactical issues to do with how the proposals were presented within the University. The possibility, though, of it simply not being a very good idea, and being rejected after reasonable examination, is not considered. The authors' perspective- that their idea fell foul of 'the ethos and traditions' of the University, as well as encountering unexpected 'internal and external pressures' (p. 164) -is a valid one; but another perspective may be equally valid in explaining why the change did not take place.

The account, by Alison Thair, Patrick Garnett and Susan King, of the introduction of a quality assurance framework at Edith Cowan University in Australia, paints a different sort of picture. Edith Cowan is, it seems, an unusual sort of university, as there is 'a universitywide commitment to systematic strategic planning, and [to] the development of [the new 
quality] framework' (p. 54). The evidence for this unanimity is not presented, but the result of introducing the new quality framework has been, apparently, the largely unproblematic establishment across the University of 'a culture of continuous improvement with regard to teaching and learning' (p. 62).

As with the Manchester case, it is hard not to wonder whether there is another story to be told here, perhaps one going beyond the platitudes about 'communicating the vision' and going on 'a journey' towards excellence (p. 62). Are all the members of the University really as committed to the new way of working as this paper suggests? Were there no dissenting voices? If not, is this not in itself a cause for concern in a university?

The most useful section of this book is the introductory chapter by Adrian Bromage, outlining the development of thinking on change management from the mechanistic checklists of the 'organizational development' theorists of the 1960s to more nuanced current sociologically-informed perspectives. But Bromage's account fails to draw attention to the political dimension underlying any change process: change management based on 'groups of stakeholders [moving] towards an outcome acceptable to all' (p. 8) assumes that such an outcome can exist: it may not. If not, then internal political factors will determine the outcome. Change management theorizing has little to say about this.

One senses that an appreciation of this difficulty underlies Lynne Hunt's thinking in her paper describing the use of 'a community development model of change'. Emphasizing the need to 'involve the hearts and minds of those involved', she characterizes her chosen model of change, with its 'nine key steps', as 'simultaneously "top-down”, "bottom-up" and "middle-out"" (p. 67). This perhaps goes some way to capture the messiness of the reality of change management, on which Hunt then tries to impose order by setting out her nine steps to heaven (establishing a policy framework, identifying stakeholders, and so forth). But although this model seems to start with a sense of needing to understand, and perhaps reorder, political power if change is to work, the conclusion is, again, an apolitical one: the organization's priorities and the needs of individuals can, with careful work, be tidily reconciled. But can they?

Managing organizational change demands knowledge which is embedded in the structures and cultures of a specific organization: prescriptions from elsewhere may offer food for thought, but the 'change cookbooks', to which Bromage refers (p. 9), will be of little help in understanding these complexities. Studying organizational change demands an appreciation of the partial (in both senses of the word) understandings that individual participants in the process will have, and an acceptance that there will always be another view. It is a pity that most of the papers in this collection did not take a more probing, self-critical approach to the interesting and important topics that they considered.

Paul Temple, Institute of Education, University of London, UK (C) 2007, Paul Temple 